\title{
Capacidade de Infiltração de água no solo em um fragmento de Mata Atlântica no município de Viçosa, MG
}

\author{
Tatiana Canazza Costenaro ${ }^{1}$ \\ Vanessa Pataro Maffia ${ }^{1}$ \\ Herly Carlos Teixeira Dias ${ }^{1}$ \\ ${ }^{1}$ Universidade Federal de Viçosa - UFV \\ Avenida Peter Henry Rolfs, s/n, Campus Universitário - 36570-000 -Viçosa - MG, Brasil \\ tccostenaro@hotmail.com \\ vpmaffia@yahoo.com.br \\ herly@ufv.br
}

\begin{abstract}
The forest vegetation have been influenced by rainfall redistribution. The trees canopy make a system of, reduction, direction and retention of water drops which arrive on soil and can affect the dynamics of the superficial drainage and the infiltration process. In this way, the covering vegetation of soil makes the maintenance of the capacity of infiltration of water in the soil, what have fundamental importance for watery recharge and control of the superficial drainage that can cause erosion in high proportions. This experiment sought to prove that there are differences between the capacities of water infiltration in the soil in ecosystems with different soil coverings: Forest at advanced regeneration stadium, Forest at initial stadium of regeneration and Trails inside the forest which makes access to the other existent experiments. The results proved the hypothesis which indicates the difference of infiltration capacity in the ecosystems is significant. Its probably makes the compact soil processes where the forests are established.
\end{abstract}

Palavras-chave: Infiltração, recursos hídricos, cobertura vegetal, regeneração.

\section{Introdução}

Na natureza a permanência dos recursos hídricos, em termos de regime de vazão dos córregos, ribeirões e rios, assim como da qualidade que emana das microbacias hidrográficas, decorre de mecanismos naturais de controle desenvolvidos ao longo de processos evolutivos da paisagem, que constituem os chamados serviços proporcionados pelo ecossistema. Um desses mecanismos, por exemplo, é a relação íntima que existe entre a cobertura florestal e a água, principalmente nas regiões de cabeceiras de drenagem, onde estão as nascentes e os nascedouros dos rios. Esta condição natural de equilíbrio vem sendo constantemente alterada pelo homem através do desmatamento, expansão da agricultura, abertura de estradas, urbanização e vários outros processos de transformação antrópica da paisagem, que alteram os ciclos biogeoquímicos e o ciclo da água. Levando em conta a população global atual e as projeções de crescimento desta população, não há dúvida de que os impactos ambientais destas transformações proporcionalmente maiores começam a ameaçar a sustentabilidade dos recursos hídricos (LIMA, 2000).

A cobertura florestal, através da interceptação, influencia a redistribuição da água da chuva, em que as copas das árvores formam um sistema de amortecimento, direcionamento e retenção das gotas que chegam ao solo, afetando a dinâmica do escoamento superficial e o processo de infiltração. Desse modo, o abastecimento das águas é favorecido e a variação de vazão ao longo do ano, reduzida, além do retardamento dos picos de cheia. Alguns pesquisadores afirmam que a floresta nativa, entre os ecossistemas vegetais, atua no ciclo hidrológico de maneira mais significativa, pois proporciona melhores condições de infiltração da água da chuva (DIAS, 2005).

Sendo assim, a cobertura florestal favorece a infiltração de água no solo por meio do aumento e/ou manutenção da porosidade do solo, o que ocasiona a passagem dessa água para 
suas camadas mais profundas por meio da percolação e assim abastece o lençol freático. Além disso, a vegetação protege o solo do impacto das gotas de chuva que, ao atingi-lo, provocam o encrostamento ou selamento superficial, o que diminui substancialmente a macroporosidade daquele solo e, portanto, a taxa infiltração de água. Ou seja, a cobertura florestal não permite que haja ou diminui significativamente a ocorrência do escoamento superficial que carrega sedimentos para o leito dos rios, podendo causar assoreamento dos mesmos e a erosão do solo.

A hipótese em que se baseia este trabalho é a de que a cobertura florestal e o pisoteio influenciam na capacidade de infiltração de um mesmo solo.

\section{Objetivo}

O objetivo com esse trabalho foi de obter dados sobre a capacidade de infiltração de água no solo da Mata do Paraíso para complementar os estudos da hidrologia do local, visando entender melhor o regime hidrológico desse fragmento florestal; bem como comparar as taxas de infiltração de um trecho de mata em estádio de regeneração mais avançado, trecho de mata em estádio inicial de regeneração, e trilhas de acesso aos experimentos ali existentes, visando discussão sobre a ação antrópica sobre o solo florestal.

\section{Metodologia}

O presente estudo foi realizado no ano de 2007 na Estação de Pesquisa, Treinamento e Educação Ambiental Mata do Paraíso, atualmente gerenciada pelo Departamento de Engenharia Florestal da Universidade Federal de Viçosa. A Reserva está inserida numa bacia hidrográfica que possui área de 194,36 ha.

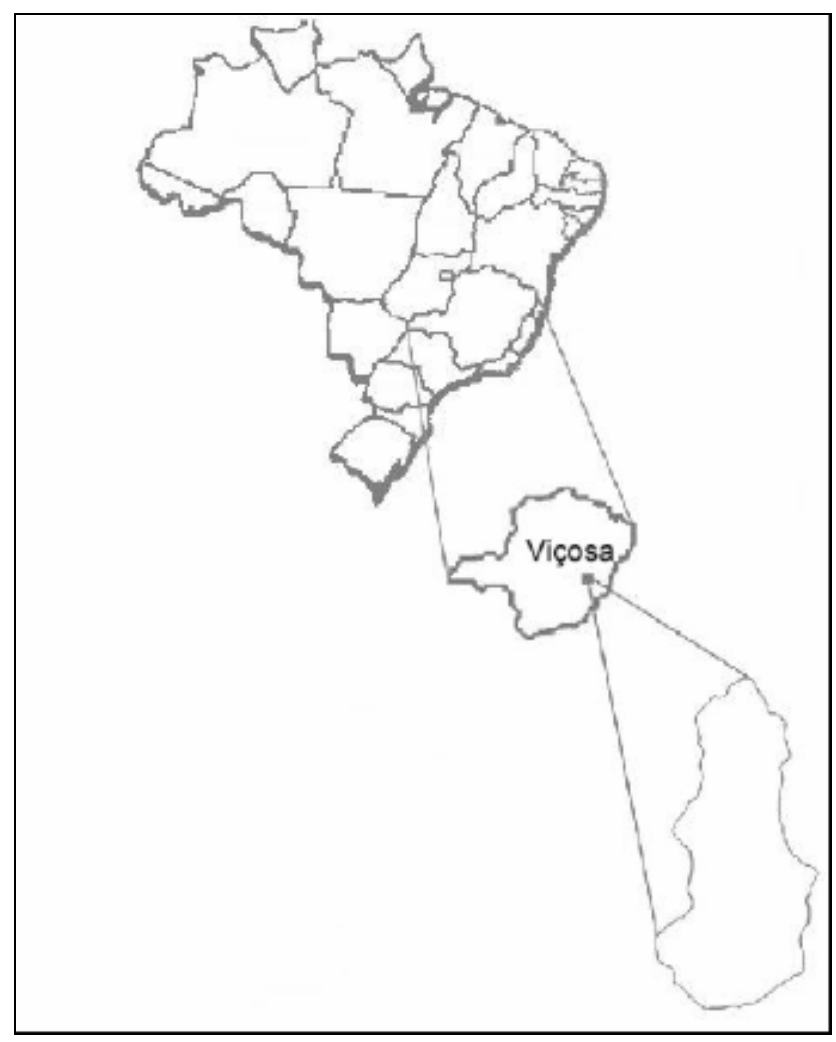

Figura 1: Localização geográfica da cidade de Viçosa, MG. 


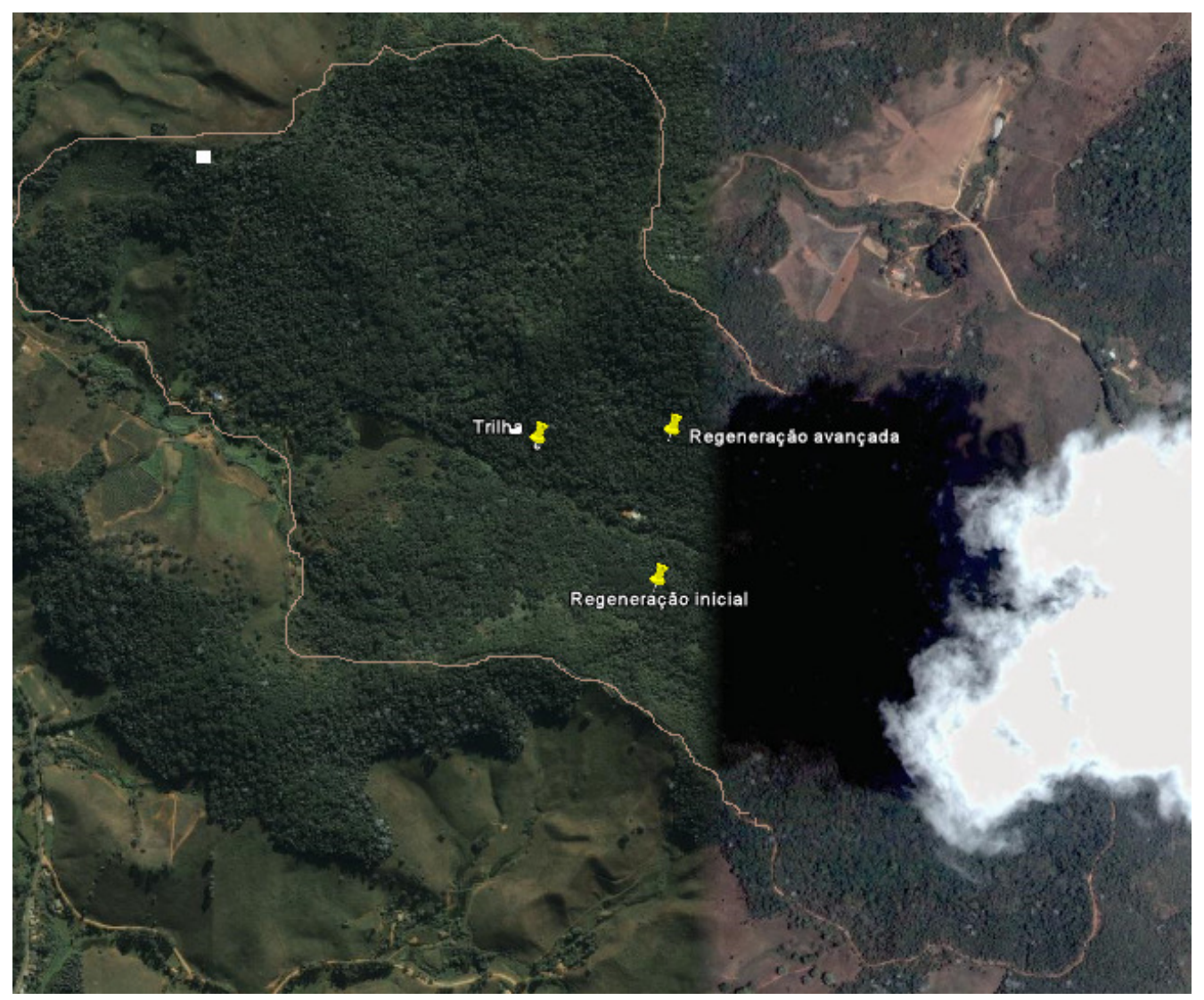

Figura 1- Foto aérea da Reserva Mata do Paraíso, indicando os pontos amostrado para medição da infiltração, Viçosa, MG.

Fonte: Google Earth

Para a determinação da capacidade de infiltração de água no solo da Mata do Paraíso foi utilizado um infiltrômetro de anéis, modelo Turf Tec, com cabo e cronômetros adaptados aos panéis como ilustrado na Figura 3.

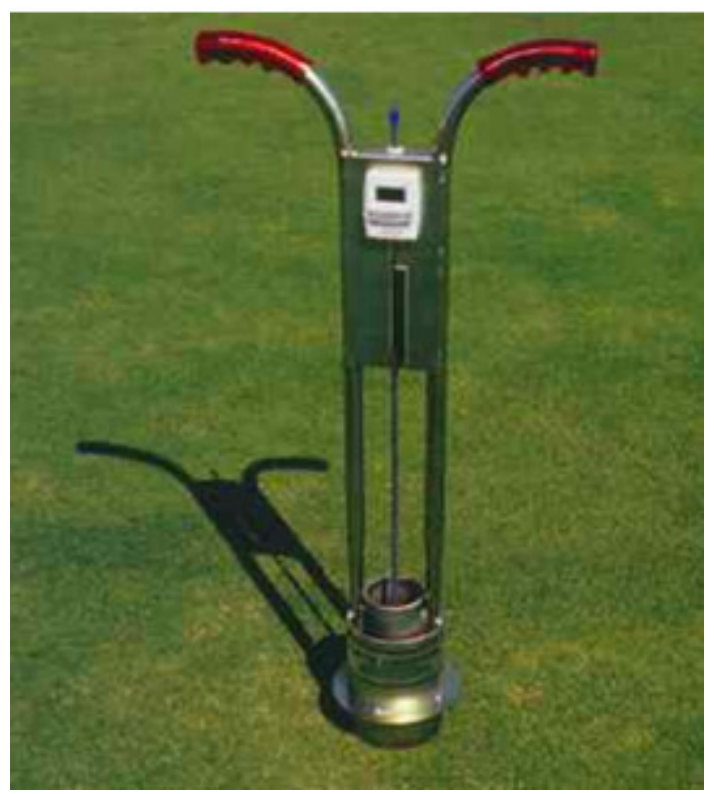


Figura 3- Foto ilustrativa do Infiltrômetro de anéis modelo Turf Tec

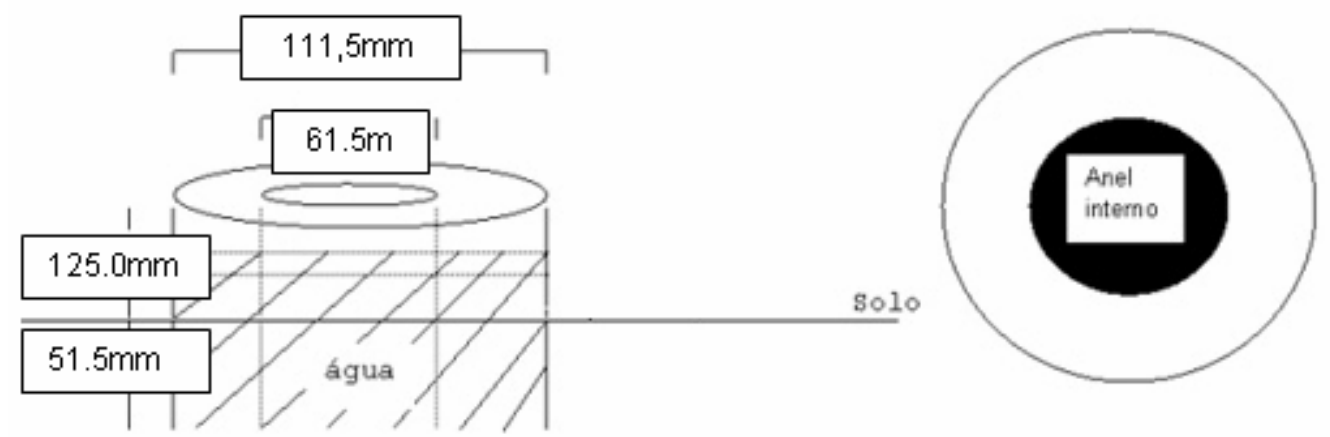

Figura 4 - Representação esquemática de um infiltrômetro de anel.

Os anéis, que são instalados de forma concêntrica, foram enterrados até $10 \mathrm{~cm}$ de profundidade. As medidas de infiltração foram feitas no anel interno. $\mathrm{O}$ teste foi finalizado quando o gasto de água em função do tempo estabilizou, nesse ponto diz-se que o solo atingiu a Velocidade Básica de Infiltração - VIB. É um método de baixo custo e prático, porém tevese o cuidado de sincronizar a leitura de lâmina e o intervalo de tempo, pois a não sincronia pode ser fonte de erro.

Foram realizadas três repetições em cada um dos diferentes ecossistemas escolhidos para comparação: mata em estádio inicial de regeneração com coordenadas 20 48'13.84"S e $42^{\circ} 51^{\prime 2} 28.93 " \mathrm{O}$, mata em estádio avançado de regeneração com coordenadas 2048'3.73"S e $42^{\circ} 51^{\prime} 27.89^{\prime \prime} \mathrm{O}$, e trilha no interior da mata com coordenadas $20^{\circ} 48^{\prime} 4.29^{\prime \prime} \mathrm{S}$ e $42^{\circ} 51^{\prime} 37.58^{\prime \prime} \mathrm{O}$.

Os pontos escolhidos para realização das medições foram aleatórios dentro de cada ecossistema.

\section{Resultados e discussão}

A coleta de dados foi realizada no período de agosto a novembro de 2007. Houveram eventos de chuva entre as medições, portanto a comparação entre Capacidades Iniciais de Infiltração da água no solo só foram possíveis entre duas das medições, o que já forneceu dados satisfatórios e passíveis de interpretação.

Os resultados da Capacidade de Infiltração de água no solo dos diferentes ecossistemas estão representados no quadro abaixo.

Tabela 1- Capacidades de infiltração de água no solo nos ecossistemas avaliados.

\begin{tabular}{|l|c|}
\hline \multicolumn{1}{|c|}{ ECOSSISTEMA } & CI (mm/h) \\
\hline Mata estádio avançado de regeneração & 1171,5 \\
\hline Mata estádio inicial de regeneração & 790,7 \\
\hline Trilha & 208,1 \\
\hline
\end{tabular}

Os resultados obtidos neste estudo mostram que há diferenças nas Capacidades de Infiltração nos diferentes ecossistemas selecionados para comparação. Esses resultados foram 
analisados baseados nas médias das três repetições de modo que a capacidade de infiltração utilizada para comparação representa bem aquele ecossistema.

No ecossistema Mata em estádio de regeneração inicial, podemos perceber a redução da Capacidade de Infiltração média em cerca de 32,5\% se comparada ao ecossistema Mata em estádio avançado de regeneração. E no ecossistema Trilha, a Capacidade de Infiltração média encontrada corresponde a uma redução de $82,2 \%$ em relação à da Mata em estádio avançado de regeneração. Esses resultados dão idéia da magnitude do impacto causado pela compactação do solo na infiltração de água.

Além dos resultados numéricos, podem-se fazer interpretações em relação ao comportamento do solo dos diferentes ecossistemas quando há um evento de chuva, de acordo com a capacidade inicial de infiltração de água naquele solo. Foi possível diagnosticar que a capacidade de infiltração inicial de água no solo do ecossistema com cobertura florestal é muito mais elevada do que a CI inicial da trilha, para uma mesma umidade inicial do solo. Os gráficos abaixo mostram as diferenças de $\mathrm{CI}$ inicial em solos com diferentes coberturas. No caso do ecossistema trilha, o solo atingiu mais rapidamente a VIB - Velocidade Básica de Infiltração, o que indica que esse solo saturará mais rapidamente que o solo sob cobertura florestal, o que acarreta em maior escoamento superficial.

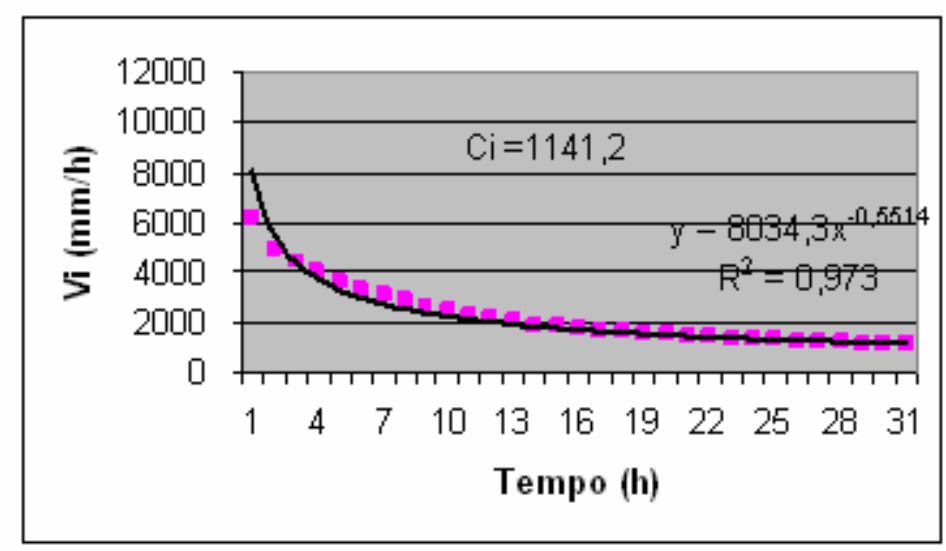

(a)

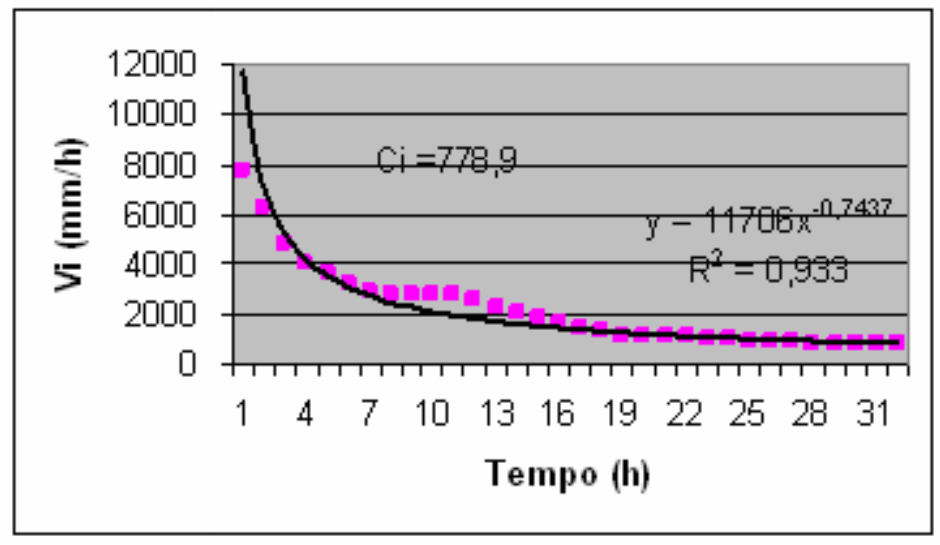

(b) 


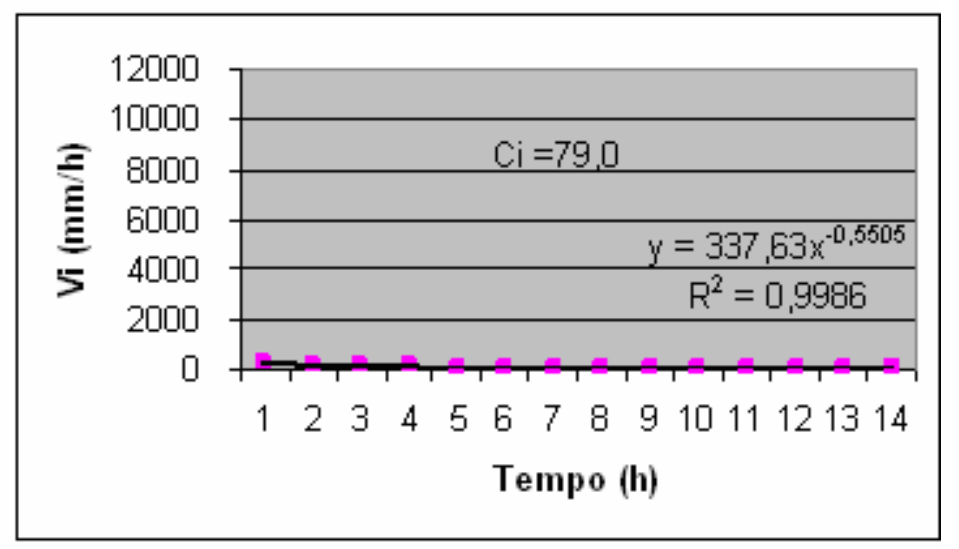

(c)

Figura 5 - (a) Curva de Velocidade de Infiltração no ecossistema Mata em estádio avançado de regeneração; (b) Curva de Velocidade de Infiltração no ecossistema Mata em estádio inicial de regeneração; (c) Curva de Velocidade de Infiltração no ecossistema trilha.

Esse resultado tem grande significado quando há uma precipitação intensa e então o solo com floresta absorve maior quantidade de água antes de começar a escoar, o que reflete diretamente na recarga dos aqüíferos e evapotranspiração da floresta, pois esta água infiltrada irá abastecer a água do solo.

Pelo diâmetro das árvores e abertura do dossel, foi possível perceber as diferenças existentes entre os ecossistemas mata em estádio inicial e mata em estádio avançado de regeneração. A presença de raízes e maior deposição de serapilheira são os principais fatores que diferem o ecossistema trilha do ecossistema mata e foram levados em consideração na análise dos resultados.

Apesar da grande cobertura de serapilheira nas trilhas, verificou-se que esta apresenta menor macroporosidade do solo, já que foram comparados trechos com o mesmo tipo e granulometria de solo, provavelmente devido ao pisoteio que gera compactação do mesmo. Num caso de precipitação intensa, portanto, esse ecossistema será o primeiro a contribuir ao escoamento superficial e também o primeiro a sofrer perdas de solo por erosão. Isso indica que a elaboração de trilhas e estradas em Unidades de Conservação ou em bacias hidrográficas deve fazer parte de rigorosos critérios no manejo integrado dessas unidades.

A diferença significativa das CI's nas matas em estádio sucessionais diferentes provavelmente se dá pelo processo de ocupação daquele local. Essas duas áreas foram citadas por SILVA JUNIOR (2004) que identificou, através de análise de fotografias aéreas da EPTEA- Mata do Paraíso, um trecho de pastagem que foi abandonada em 1963 e hoje corresponde à floresta secundária com trechos de dossel descontínuo e alta incidência de lianas. Outro trecho da Reserva caracteriza-se como uma floresta em estádio avançado de sucessão, e segundo antigos moradores locais, nesse trecho da floresta ocorreu no passado a extração seletiva de árvores de maior valor comercial, porém nunca houve corte raso. Conclui-se, portanto, que o pisoteio do gado, mesmo após 39 anos ainda apresenta suas consequiências nos dias atuais, com a compactação do solo que inibe a infiltração de água, apesar da presença da floresta na área correspondente. 


\section{Conclusão}

- Os resultados obtidos confirmam a hipótese de que a cobertura florestal e o pisoteio influenciam na capacidade de infiltração de um mesmo solo.

- As capacidades de infiltração de água no solo dos ecossistemas Mata em estádio inicial de regeneração, Mata em estádio avançado de regeneração e trilha de acesso aos experimentos são, respectivamente $790,7 \mathrm{~mm} / \mathrm{h}, 1171,5 \mathrm{~mm} / \mathrm{h}$ e $208,1 \mathrm{~mm} / \mathrm{h}$.

- Há uma perda na CI média na Mata em estádio inicial de regeneração de 32,5\%, e na trilha de 82,2\%, em relação à CI média da Mata em estádio avançado de regeneração.

- Esses resultados devem-se, provavelmente, à compactação do solo, uma vez que a trilha está constantemente sofrendo pisoteio e a Mata em estágio inicial de regeneração apresenta histórico de compactação devido ao pisoteio de gado.

- Essa compactação do solo diminui a capacidade de infiltração de água durante um evento de chuva, o que pode provocar escoamento superficial e em casos mais graves, erosão daquele solo e conseqüente assoreamento de cursos d'água.

superficial representa $0,17 \%$.

\section{Agradecimento}

Os autores agradecem à Fundação de Apóio a Pesquisa do Estado de Minas Gerais, FAPEMIG, por financiar a participação no SERHIDRO.

\section{Referências}

DIAS, H.C.T. ; OLIVEIRA JUNIOR, J.C. Precipitação efetiva em fragmento secundário da Mata Atlântica. Revista Árvore, Viçosa- MG, v. 29, n.1.p.9-15, 2005.

LIMA, W.P. Importância das florestas para a produção de água. In: SIMPÓSIO SOBRE RECUPERAÇÃO DA COBERTURA FLORESTAL DA BACIA DO RIO CORUMBATAÍ. Anais... Piracicaba, IPEF/ESALQ, 2000.

SILVA-JÚNIOR, W. M. et al. Regeneração natural de espécies arbustivo-arbóreas em dois trechos de Floresta Estacional Semidecidual, Viçosa, MG. Scientia Forestalis, v.66, p.169-179, 2004. 